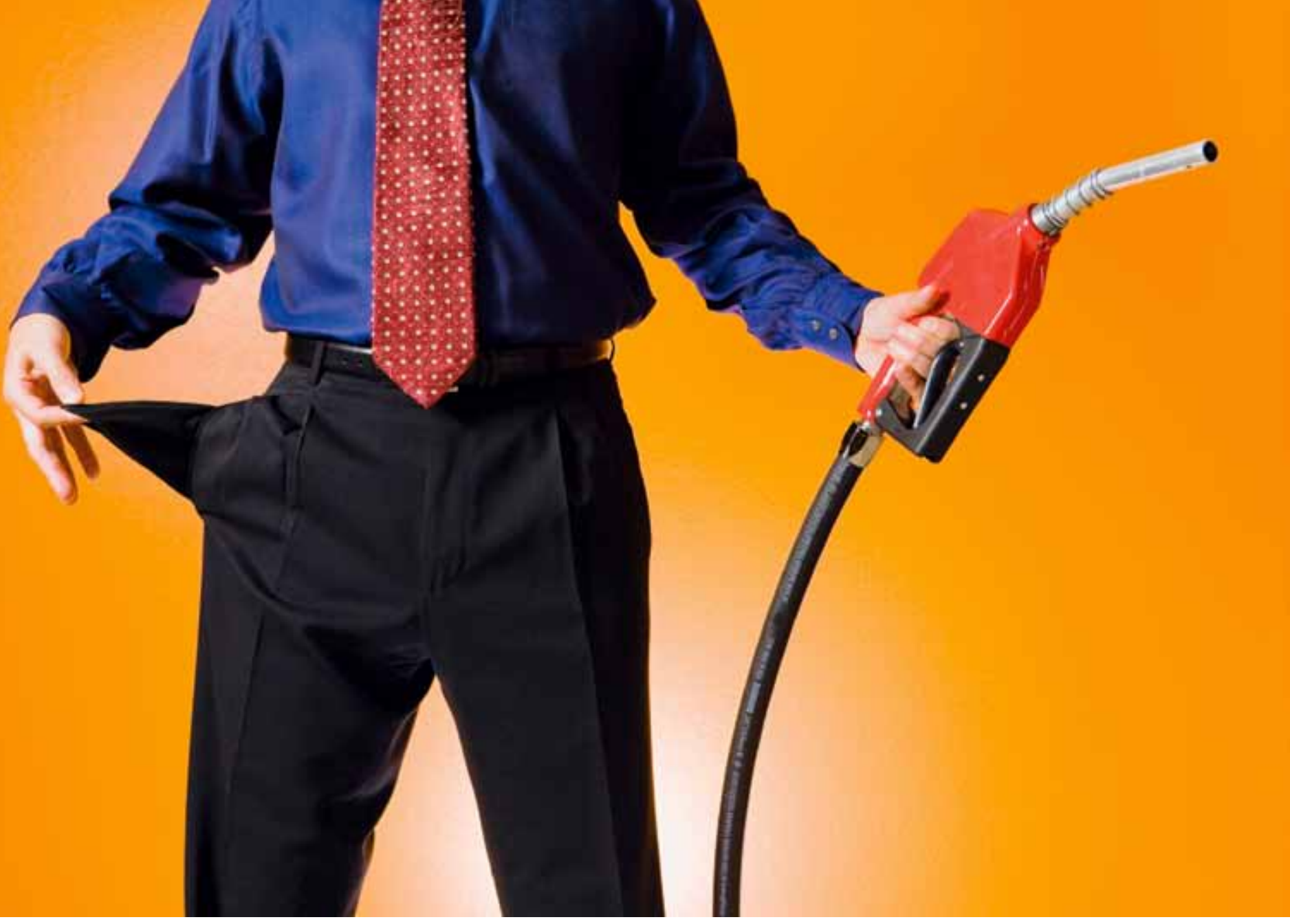

4

\section{¿Quién paga el impuesto a la gasolina?}

Dos pistas: ni la clase media ni la clase baja. ¿Por qué, entonces, algunos parlamentarios insisten con tanto ahínco en rebajarlo?

Por Claudio Agostini*
Hasta marzo del año pasado, el impuesto a los combustibles -en rigor, el impuesto las gasolinas- era de 6 UTM por cada metransitoriamente por dos años primero a 4,5 transitoriamente por dos años, primero a 4,
UTM y luego a 3,5 UTM. A partir del junio $d$ de este año volvió a 4 UTM, pero gracians a preeste año volvió a 4 UTM, pero gracias a pre-
siones se le fijó un tope de 4,5 UTM al menos hasta abril del 2010.

Este es un impuesto eficiente. La teoria económica y la evidencia empirica en muchos paises muestran que un impuesto a las gasolinas mejora la asignación de los recursos, ya que reduce los efectos negativos que producen los automóviles en la contaminación del aire y además disminuye congestión y los accidentes porque aumenta el costo de manejar, tanto para los vehículos nuevos como para los usados. Además, incentiva la compra de automóviles que son Lo ideal sería disponer un impuesto por el kilometraje anual de cada vehiculo y que fuera más alto en Santiago, ciudad con niveles de contaminación y congestión mucho más altos que el resto de Chile. Obviamente seria imposible fiscalizar un impuesto asi por eso la opción actual de colocar un impuesto por metro cúbico de gasolina es razonable.

Un impuesto "contra" Ia clase medio En el caso de Chile, la evidencia muestra que el impuesto a las gasolinas es progresivo: los hogares de ingresos mas altos pagan proporcionalmente más que los de ingresos

Sin embargo, los parlamentarios han desplegado transversalmente una fuerte oposi-

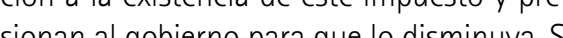
bien el gobierno logró resistir las presionesy el impuesto volvió a 4 UTM en junio pasado ta como correspondía de acuerdo a ley no logró detener todas las presiones y se impso un limite de 4.5 UTM hasta abril de 2010. En esa fecha veremos si el impuesto vuelve a las 6 UTM de antes o las presiones de parlamentarios y la Asociación de Distribuidores de Combustibles lo impiden.

Quienes presionan por la disminución del impuesto argumentan que defienden la clase media, la "más afectada" por el impuesto. En las paginas web del Congreso y de varios parlamentarios podemos ver declaraciones como: "No hay duda que el impuesto especifico a los combustibles está ahogando a la clase media", "el uso de automóviles no es un lujo sino una fuente de trabajo" $Y$ "una medida de este tipo [rebaja del impues en directo beneficio de la clase media". tes dada la realidad del pais y la inapelable evidencia que entregan los datos. De par-

tida, asumen que una rebaja de impuestos se traduce automáticamente en una rebaja equivalente en los precios a consumidores, lo cual no tiene por qué ser cierto. En laño 2000 en Estados Unidos, el impues las gasolinas se redujo en un 5\% durant un año en Illinois y en Indiana para aliviar los consumidores, y el resultado fue que tos precios bajaron sólo 2.7\%. Esto ocurre e para Chile discutir la existencia de poder de mercado en la industria de los combustibles, incluyendo a Enap y las distribuidoras, que la baja de impuestos. De hecho, la evidencia para Chile es que cuando el precio del petroleo sube, los precios a consumidor final ajustan rápidamente, pero cuando el precio del petroleo baja, los precios a los consum

En 2007, en comunas de altos ingresos como vor mente. En comunas pobres como Carahue, en la IX Región, y La Pintana, en la Región Metropolitana, habia menos de tres.

En 2006 a a enas el 27\% de los hogares tenía automóvil, de los cuales $70 \%$ corresponde a los dos quintiles de más altos ingresos. Si miramos la distribución de los automóviles por quintil de ingreso, la Casen 2006 muestra que en el quintil de más altos ingresos hay 93 automóviles por cada 100 hogares, mientras que en el quintil más pobre hay sólo trece.

El gráfico a la derecha muestra el porcentaje de hogares que tiene automovil por deci de ingreso: el $67 \%$ de los hogares del decil de más altos ingresos tiene auto, mientras que menos del $8 \%$ de los hogares del decil más pobre tienen automóvil. Es importante notar tambien que la fracción de hogares con auto cae dramáticamente con el ingreso y ya en e) menos de la mitad alos hingsos (decil 9) menos de la mitad de los hogares tienen

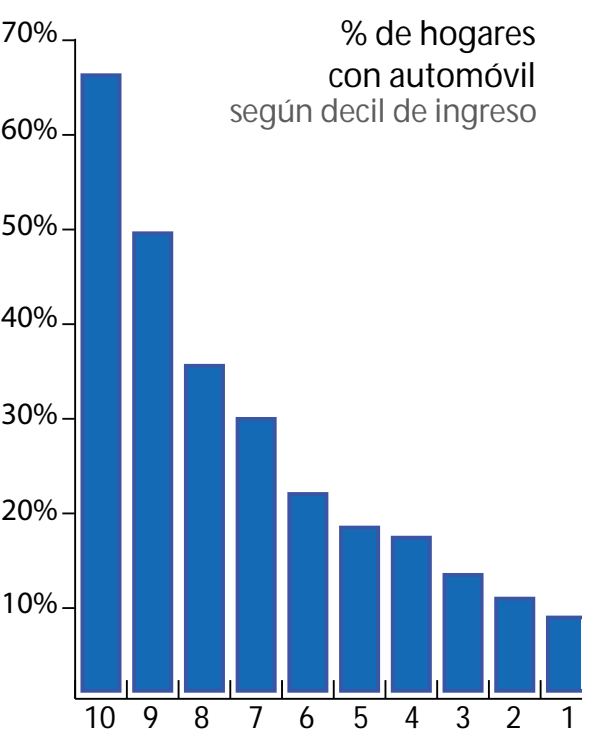

5 


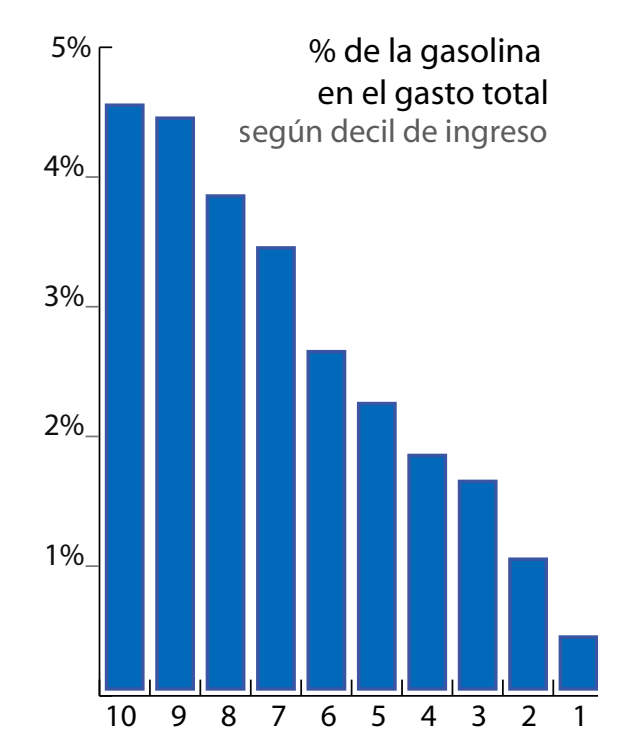

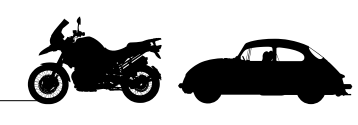

Si consideramos ahora el gasto de los ho- Ello puede pasar porque el mundo que los gares, de acuerdo a la última Encuesta de rodea es efectivamente uno de personas de (resupuestos familares del InE (ginfico de ingresos altos, como ellos mismos, donde la izquierda), el gasto en combustibles repre- todos tienen un auto o más, por lo que les senta 4,2\% del gasto total de los hogares del resulta dificil creer, por ejemplo, que en Chile mas pobre, lo cul hace que elimpuesto sea más pobre, lo cual hace que el impuesto sea evehiculo.

En cualquiera de las dos alternativas es

Consto en vez ingreso gaturión permanente de los hogares, que los gastos fluctúan menos que los ingresos en el tiempo. En el gráfico siguiente se muestra la distribución del gasto en combustibles de los hogares por decil de ingresos gasta un 4,5\% de sus gastos totales mensuales en gasolina, para el decil de menos ingresos el gasto en gasolina representa apenas un $0,4 \%$ de sus gastos totales mensuales. Esta distribución muestra que impuesto a las gasolinas es progresivo lo pagan en mucho mayor proporción los hogares de ingresos más altos, en particular los de los deciles 9 y 10, es decir, el 20\% de más altos ingresos.

Clase media con dos autos por familia Los números no mienten: el impuesto los combustibles lo paga principalmente la clase alta de este pals y no la clase media. La pregunta entonces es como legislan nuesnos parlamentarios, que en sus argumentos para la decisión

Una alternativa es que ni ellos ni sus asesores consideran los datos, lo cual serí preocupante dado que toman decisiones que afectan a todos los chilenos Uno se preguntaria en ese caso, qué hacen los asesores legislativos de los parlamentarios, que no les entregan la información minima disponible para legislar seriamente.

Otra posibilidad es que si conozcan los datos, pero consideren que la clase media corresponde al 10020 por ciento de más altos ingresos, lo cual reflejaria una distorsión importante en la percepcion de la realidad. tenen no son capaces de proveerlos de los datos básicos que requieren conocer para legislar tal vez llegó el momento de cambiar el modelo de asesorías en vez de financiar con impuestos de todos los chilenos a un grupo de asesores legislativos que no hacen bien su trabajo, habría que implementar un organismo asesor autónomo y no partidista, tal como existe en .

lado, algunos parlamentarios tenen una distorsión de la realidad, creen que todo Chile es como el mundo que los rodea y leislan de acuerdo a ello, es bueproxicion sopara la percepción de la realidad de cada respecto a como es mayor transparenci specto a cómo vota cada parlamentario sones como en la sal y también respecto las personas e instituciones que recibe en a las personas e insticuciones que recibe en de campañ. Sin duda queda mu por avanzar en esa materia y recién este año nos nemos enterado, por ejemplo, de quienes son los asesores de algunos parlamentarios. Otra forma importante de avanzar en esta rol y no solamente cuestionen a los parlamentarios e informen cómo votaron y a que bbistas recibieron, sino que los confronten con datos que muestran que muchas de sus firmaciones no se sostienen en la realidad.
Será mucho pedir? no que los votantes lo sepan antes de las proximas elecciones. En este uiltimo caso,

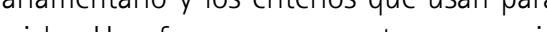

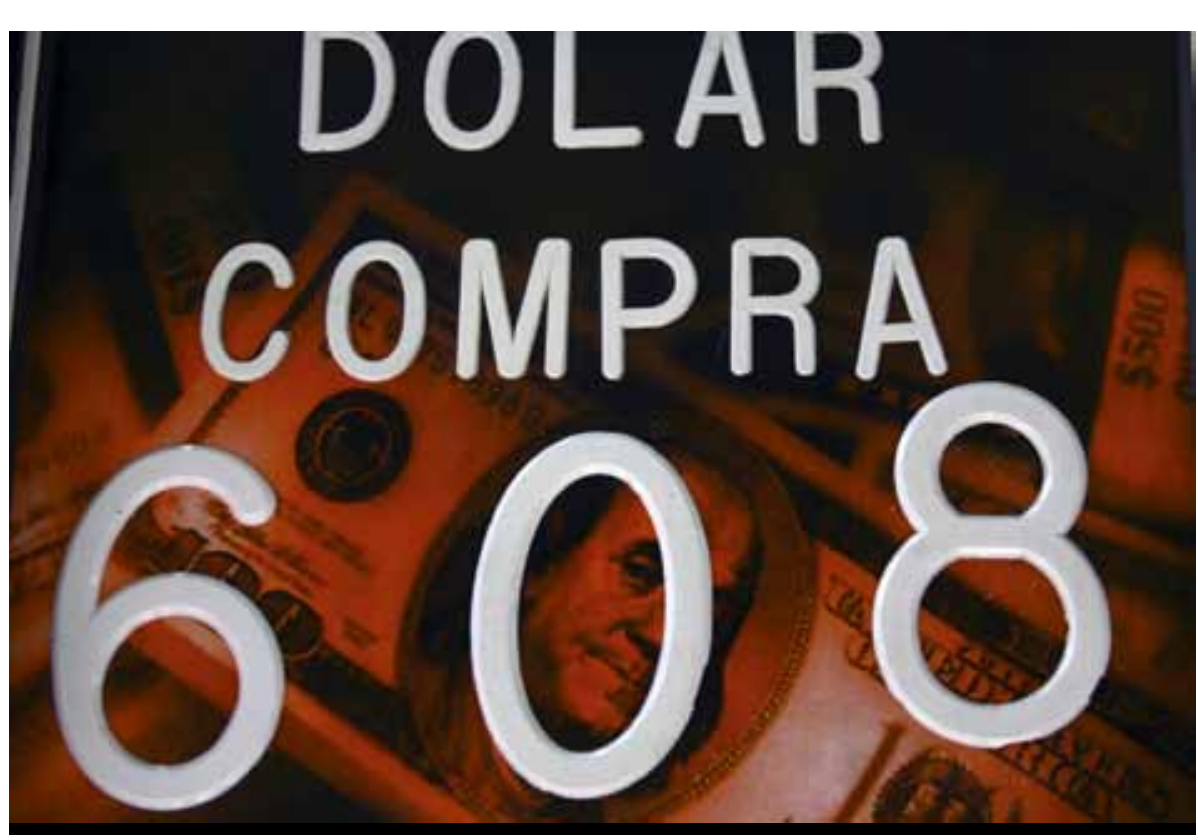

\section{¿Hacia dónde va el peso chileno?}

Predecir la caída de 13.8\% del tipo de más a los bienes transables internaciocambio nominal del US Dolar en este nalmente". Así, los precios de los proaño habria sido, en el mejor de los ca- ductos transables (desde los berries hassos, un afân ilusorio (y en el peor, una ta los blackberries) caerian en relación asesoria fraudulenta). Siempre habra al- a los de aquellos bienes y servicios noguien que acierte pronosticos, pero no transables, esto es, los que circulan solo es posible saber si ello es genialidad o en el pais (desde ladrillos a gásfiters). suerte. Por lo demás, la competitividad ¿Por qué? Porque a los no-transables de un pais se mide por su tipo de cam- no les llegan las disminuciones de cosbio real (ha caido $11.8 \%$ en el año) y es tos que impone la competencia extern aun menos pronosticable, pues depende a variables de suyo exogenas (como la paridad Euro-Dólar y la inflación de en una economia abierta, y termin (n) bomo el tipo rciales). de cambio real refleja el cuociente entre sería, divisa deberá caer cuando crecemos.

creo, levantar la vista y asociar el tipo En realidad, la evidencia empírica es A cialmente al gasto y productividad del sector público. tudio del NBER (Takatoshi, 1997) encuentra resultados disimiles entre paises APEC. Harberger (2003) llega a algo si-

Se suele admitir en la literatura que Chile lo hará desde 2010) deberán soportar la caída secular de su tipo de cambio real.

milar en otros países crecedores. La explicación plausible es que las De ganancias de productividad pueden impulsarse también desde los sectores bienes no-transables. Y aunque se pien-

(efecto Balassa-Sal son) reza así: "Cuando se crece, los aua a veces en estos últimos solo con ad benefician servicios de peluqueros o notarios,

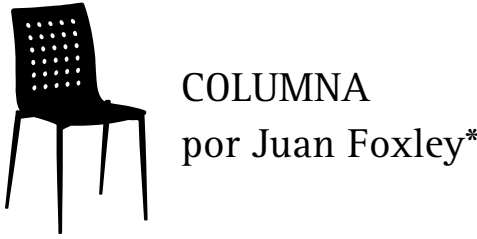

"Director Diplomado de Finanzas, Facultad os, UAH.

alidad los no-transables reúnen a ins estatales. Por cieto toda la gestión pública es modernizable en Chile. Su productividad puede saltar, tal como lo hizo en las ultimas décadas a a prir de manufactura y minena a partir de la apertura aléco exterion, forma del sector público que respondan al nuevo desafío.

Oe

Decano: Jorge Rodriguez Gross.
Fono Facultad: 6920277 e-mail: jrodrigu@uahurtado.cl Producción OE: Comunicar, Escuela de Periodismo UAH. OE es una revista de circulación gratuita. 